\title{
The global ocean circulation on a retrograde rotating earth
}

\author{
V. Kamphuis, S. E. Huisman, and H. A. Dijkstra \\ Institute for Marine and Atmospheric research Utrecht, Utrecht University, Utrecht, The Netherlands \\ Received: 3 September 2010 - Published in Clim. Past Discuss.: 3 November 2010 \\ Revised: 16 February 2011 - Accepted: 12 March 2011 - Published: 9 May 2011
}

\begin{abstract}
To understand the three-dimensional ocean circulation patterns that have occurred in past continental geometries, it is crucial to study the role of the present-day continental geometry and surface (wind stress and buoyancy) forcing on the present-day global ocean circulation. This circulation, often referred to as the Conveyor state, is characterised by an Atlantic Meridional Overturning Circulation (MOC) with a deep water formation at northern latitudes and the absence of such a deep water formation in the North Pacific. This MOC asymmetry is often attributed to the difference in surface freshwater flux: the Atlantic as a whole is a basin with net evaporation, while the Pacific receives net precipitation. This issue is revisited in this paper by considering the global ocean circulation on a retrograde rotating earth, computing an equilibrium state of the coupled atmosphere-ocean-land surface-sea ice model CCSM3. The Atlantic-Pacific asymmetry in surface freshwater flux is indeed reversed, but the ocean circulation pattern is not an Inverse Conveyor state (with deep water formation in the North Pacific) as there is relatively weak but intermittently strong deep water formation in the North Atlantic. Using a fullyimplicit, global ocean-only model the stability properties of the Atlantic MOC on a retrograde rotating earth are also investigated, showing a similar regime of multiple equilibria as in the present-day case. These results indicate that the present-day asymmetry in surface freshwater flux is not the most important factor setting the Atlantic-Pacific salinity difference and, thereby, the asymmetry in the global MOC.
\end{abstract}

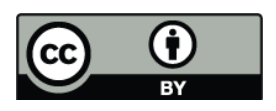

Correspondence to: S. E. Huisman (s.e.huisman@uu.nl)

\section{Introduction}

The extent and the connections between the main ocean basins have dramatically changed over the Cenozoic due to continental movement. Very likely, this has induced changes in the global ocean circulation pattern, in particular, in the locations of deep-water formation (e.g. Thomas, 2004). Indeed, there are many indications from various geological data that the global meridional overturning circulation (MOC) in the Eocene, Oligocene or Miocene was substantially different from the present-day circulation (see Von der Heydt and Dijkstra, 2008 for an overview). An understanding of how factors, such as continental geometry and surface forcing, have affected these past circulation patterns requires knowledge on why the present-day circulation is as we observe it (Wunsch, 2010).

At present, the global MOC is characterised by strong deep water formation in the North Atlantic Ocean and the absence of deep water formation in the North Pacific Ocean (Gordon, 1986). Near-surface currents transport water from the South Atlantic across the equator and into the subpolar North Atlantic. In this region, the relatively warm and saline water is cooled by heat loss to the cold atmosphere. In the Greenland and Labrador Seas, dense deep water is formed. This dense water is transported back to the Southern Ocean in deep western boundary currents in the Atlantic Ocean. Eventually this deep water is returned to the surface by upwelling, which is driven by both mixing in the ocean's interior and the westerly winds over the Southern Ocean (Kuhlbrodt et al., 2007). The Atlantic MOC is an important feature of the climate system, since it transports about $1 \mathrm{PW}$ of heat $\left(1 \mathrm{PW}=10^{15} \mathrm{~W}\right)$ northward at $25^{\circ} \mathrm{N}$ (Ganachaud and Wunsch, 2000).

Published by Copernicus Publications on behalf of the European Geosciences Union. 
The Atlantic-Pacific asymmetry in deep water formation is explained by the salinity contrast between the subpolar North Pacific and the subpolar North Atlantic: the subpolar North Pacific surface water is not dense enough to sink, even when it is cooled to the freezing point (Marotzke, 2000). It is often argued that this salinity contrast is determined by the observed difference in surface freshwater flux $(E-P$, i.e., net evaporation minus precipitation) between the North Pacific and the North Atlantic. This difference in $E-P$ is mainly due to the higher evaporation rate per unit area over the North Atlantic (thereby making $E$ the most important factor in setting the difference between the freshwater budget of the Atlantic and Pacific) as the precipitation rate per unit area has been estimated to be similar over the subpolar gyres (EmileGeay et al., 2003). However, the higher evaporation rate over the North Atlantic is mainly caused by the higher sea surface temperature, which is a consequence of the meridional heat transport associated with the Atlantic MOC. Therefore, this explanation contains a circular argument and we may still pose the question: why is there currently a global ocean circulation with such a strong Atlantic-Pacific MOC asymmetry?

Arguably, one of the main ingredients to answer this question is the strength of the salt-advection feedback (Stommel, 1961), through which salinity anomalies may be amplified. In short, an increase in the subpolar near-surface salinity enhances deep water formation. Therefore, the advection of salty subtropical water into the subpolar region is enhanced, further increasing the near-surface salinity in the regions of deep water formation. There is also a negative temperature-advection feedback, but as temperature anomalies are strongly damped by the overlying atmosphere compared to salinity anomalies, the salt-advection feedback can lead to relatively rapid changes of the MOC.

In a hierarchy of models, ranging from the two-box model of Stommel (1961) to climate models of intermediate complexity (Rahmstorf et al., 2005), this salt-advection feedback creates a multiple equilibria regime of the MOC. In this multiple equilibrium regime, at least two stable states of the global MOC co-exist in realistic geometry: the Conveyor state (or "on"-state, with a vigorous Atlantic meridional overturning circulation and North Atlantic Deep Water formation) and a so-called Southern Sinking state (or "off"state) for which deep water formation only takes place in the Southern Ocean. In the Conveyor state of this multiple equilibrium regime, the Atlantic MOC is self-sustaining, providing itself with the northward salt transport required for deep water formation. When the strength of the freshwater flux is varied over the northern North Atlantic, two saddle-node bifurcation points bound the region of the multiple and unique state (either Conveyor or Southern Sinking) regimes (Dijkstra and Weijer, 2005), and abrupt transitions between these states can occur.

In an idealized ocean-only model of two (similar-size) basins which are connected by a channel at high southern latitudes, four different equilibrium solutions of the ocean circulation are found under an equatorially symmetric and zonally independent freshwater flux (Marotzke and Willebrand, 1991; Huisman et al., 2009). These four states are called Conveyor, Inverse Conveyor, Southern Sinking and Northern Sinking. When external asymmetries in Atlantic and Pacific geometry and equatorial asymmetries in surface freshwater flux (Zaucker et al., 1994) are taken into account, it is expected that some of these four states can no longer be maintained as steady states. For example, the impact of asymmetries on the steady-state patterns of the Atlantic MOC in a two-dimensional model (Dijkstra et al., 2003) has shown that a slight equatorial asymmetry in $E-P$ can lead to the disappearance of the Southern Sinking solution. The presence of open gateways (Von der Heydt and Dijkstra, 2008) or other geometrical asymmetries, like a further northward extent of the Atlantic and a wider Pacific (Hughes and Weaver, 1994) have also been shown to lead to the preference of specific solutions over others. A recent study of Schmittner et al. (2011) shows that mountain ranges could play a critical role in selecting a circulation pattern.

Therefore, at least two different views on the AtlanticPacific MOC asymmetry can be proposed:

i. There is only one possible equilibrium circulation pattern in the ocean under any atmospheric surface forcing and continental geometry (including the present forcing and geometry). Multiple equilibria do not play a role in setting the Atlantic-Pacific salinity contrast. This contrast is set by the external forcing asymmetries.

ii. Out of a number of possible equilibria, the present-day weak external forcing asymmetries induce a strong preference for the Conveyor state, with a strong AtlanticPacific salinity contrast, due to the positive salt feedback.

The essential difference between these two views is the role of multiple equilibria and, hence, of the relative importance of the salt-advection feedback with respect to external forcing asymmetries in the global MOC.

Although it is difficult (if not impossible) to determine all MOC equilibrium states in a state-of-the-art Global Climate Model (GCM), such as those used in the IPCC-AR4 (WG1, Chapter 8), we can perform simulations with such a model to try to falsify aspects of (i). One of the consequences of (i) is that if the external asymmetries are reversed (Atlantic versus Pacific), an Inverse Conveyor solution is expected. Using a global ocean-only model, Huisman et al. (2010b) determined an equilibrium state under a Levitus surface salinity field which is reversed between the Atlantic and the Pacific (the Pacific is made as salty as the Atlantic and vice versa). Under the freshwater flux diagnosed from this equilibrium, where the North Atlantic receives net precipitation, they show that a stable ocean circulation state with deep water formation in the North Atlantic still exists. While this is 
quite a contrived situation, it already shows that the asymmetries in the surface freshwater flux may not be crucial for the Atlantic-Pacific MOC asymmetry.

A nice way to generate different asymmetric surface freshwater flux forcing conditions in a coupled ocean-atmosphere context is to investigate climate on an earth which is rotating retrograde. The $\mathrm{MOC}$ on a retrograde rotating earth has been examined before (Smith et al., 2008, EGU Poster) using the FAMOUS model, in the context of the problem of the Atlantic-Pacific MOC asymmetry. Interestingly, the basic mechanisms which control the MOC and the salt-advection feedback, are invariant to a reversal of the earth's direction of rotation.

Given a positive meridional density difference $\Delta \rho$, the geostrophic and hydrostatic balance give for the zonal velocity $\boldsymbol{u}$

$f \frac{\partial \boldsymbol{u}}{\partial \boldsymbol{z}} \approx \frac{g}{\rho_{0}} \frac{\Delta \rho}{L}$

where $L$ is a typical horizontal basin length scale, $g$ is the gravitational acceleration, $\rho_{0}$ the reference density of sea water and $z$ is the vertical coordinate. The parameter $f$ is the local Coriolis parameter $(f=2 \Omega \sin \theta)$, with $\Omega$ representing the angular frequency of the earth's rotation and $\theta$ is the geographic latitude. For a retrograde rotating earth, the zonal surface velocity $\boldsymbol{u}$ is negative in the North Atlantic. Hence, water will be transported westwards at the surface providing a higher surface pressure in the west compared to the east. A negative zonal pressure gradient $\Delta p / L$ will result and the meridional geostropic velocity $v$ is determined by

$f \boldsymbol{v} \approx \frac{1}{\rho_{0}} \frac{\Delta p}{L}$

Again in the North Atlantic, a positive $v$ results, which is similar to the response to a positive $\Delta \rho$ on a prograde rotating earth. As the salt-advection feedback is associated with the meridional transport of salt, due to salinity perturbations which affect the MOC, it is also invariant with respect to a rotation reversal.

However, the atmospheric circulation is not the same for prograde and retrograde rotation and patterns of precipitation and evaporation over the Atlantic and the Pacific are very different. For example, the moisture transport by the trade winds over the Central American isthmus is eastward on a retrograde rotating earth, salinifying the North Pacific and freshening the North Atlantic.

We, therefore, expect that the Atlantic-Pacific asymmetry in sea surface freshwater flux is reversed on a retrograde rotating earth and, hence, under view (i) one would expect an Inverse Conveyor state, which was also found by Smith et al. (2008, EGU Poster). So what looks like an academic exercise to investigate climate on a retrograde rotating earth may actually provide an interesting test for the falsification of view (i). In this paper, we show results (Sect. 3) of the global MOC on a retrograde rotating earth using the coupled atmosphereocean-land surface-sea ice model CCSM3, which will be shortly described in Sect. 2. In addition, we analyse the stability properties of the global MOC on a retrograde rotating earth in a global ocean-only model (Sect. 4). The results are summarized and discussed, in particular, the implications for ocean circulation patterns in the past, in Sect. 5 .

\section{Model and experimental design}

The climate of the earth is simulated with the coupled atmosphere-ocean-land surface-sea ice model CCSM3 (Community Climate System Model, version 3, Collins et al., 2006a). The atmosphere component (CAM3, Collins et al., 2006b) has a horizontal T42 grid, which provides a resolution of approximately $2.8^{\circ}$ in both longitude and latitude, and 26 hybrid coordinate levels in the vertical. The ocean component is based on POP (Parallel Ocean Programme, Smith and Gent, 2004). It has a curvilinear grid which contains 100 longitudinal grid points (a resolution of $3.6^{\circ}$ ), 122 latitudinal grid points and 25 vertical levels. The sea ice is simulated in a thermodynamic sea-ice model (CSIM, Briegleb et al., 2004), which runs at the same resolution as the ocean model. The land component (CLM, Dickinson et al., 2006) runs at the same resolution as the atmospheric model. The CCSM3 model does not contain a dynamical vegetation model and has a representation of subgrid-scale heterogeneity of surface types.

We performed a 500 year control simulation indicated by PRO (for prograde rotation), with a $\mathrm{CO}_{2}$ concentration of 355 ppmv (the observed global mean value in 1990) and present-day boundary conditions. The initial ocean temperature and salinity for PRO were obtained from Levitus (1982). Both the maximum Atlantic MOC and maximum Pacific MOC values are plotted versus time in Fig. 1. After 500 years of simulation, the global meridional overturning circulation is in a stable quasi-equilibrium state. The global mean surface temperature equilibrates at $14.7^{\circ} \mathrm{C}$, similar to earlier CCSM3 results (Meehl et al., 2004).

In the second simulation with CCSM3, indicated by RETRO, only the sign of the rotation rate $\Omega$ is switched from +1 to -1 ; a simulation of global climate on a retrograde rotating earth results. The initial temperature and salinity for RETRO are also obtained from Levitus (1982). The MOC is found to be in quasi-equilibrium after 500 model years (Fig. 1), but the simulation was continued for another 500 years, showing no apparent climate drift. In the next section, the quasi-stable equilibrium states after 500 years in PRO and RETRO (averages of years 400-500 of integration) will be compared. 

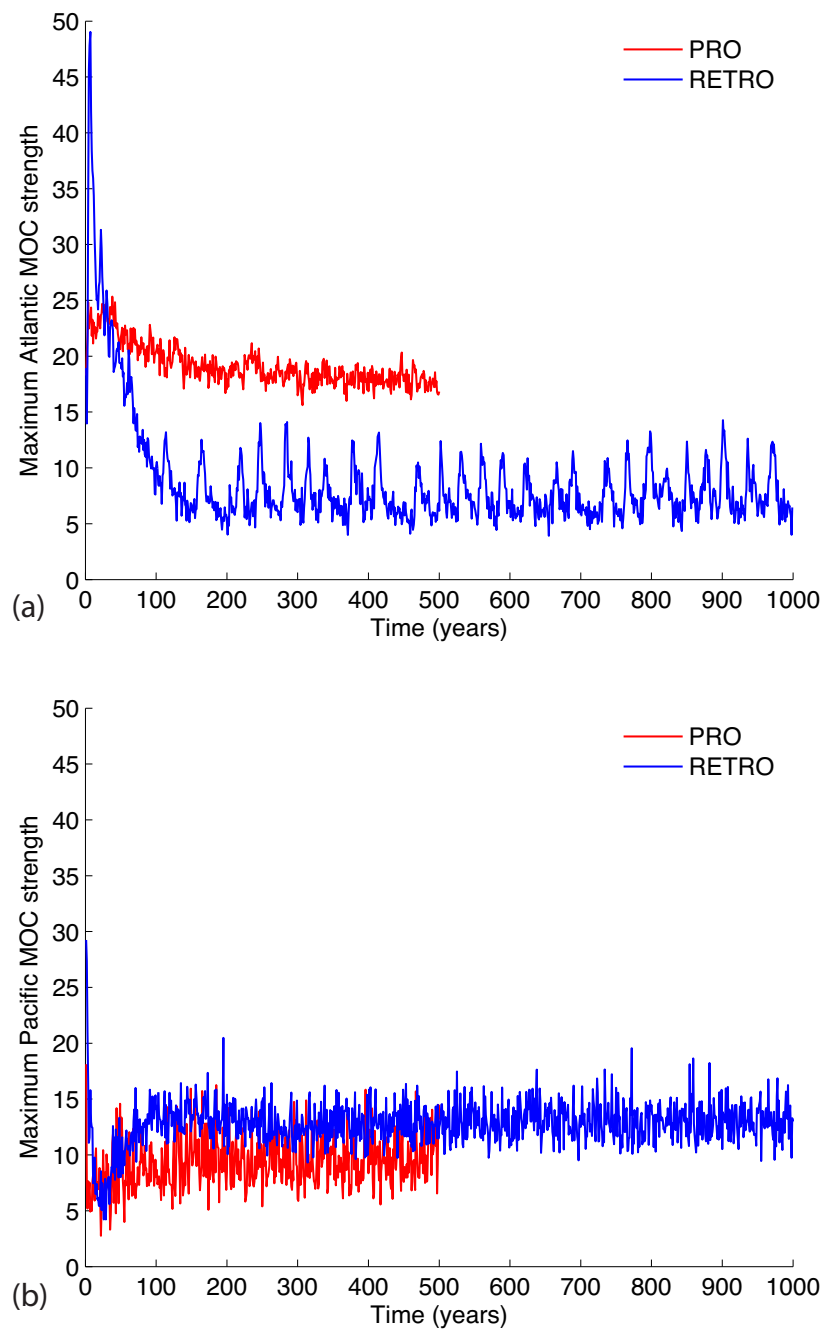

Fig. 1. The strength (in Sv) of the (a) maximum Atlantic and (b) maximum Pacific meridional overturning circulation (below $500 \mathrm{~m}$ ) as a function of time (in years) for PRO (500 year simulation, red) and RETRO (1000 year simulation, blue). After 500 years, the Atlantic MOC is in a quasi-stable equilibrium for both PRO and RETRO.

\section{The global MOC on a retrograde rotating earth}

To illustrate one of the important consequences of a reversal of the earth's direction of rotation, the surface wind patterns for both PRO and RETRO are shown in Fig. 2. Because the Coriolis acceleration changes direction and the equatorto-pole density gradient does not change, the thermal wind relations show that the wind patterns should reverse. This is indeed the case in CCSM3 (Fig. 2b); the trade winds are eastward and the midlatitude winds are westward. The magnitude of the wind velocity is similar for PRO and RETRO.

The sea surface salinity field and the sea surface temperature field for the PRO and RETRO quasi-equilibrium solutions are shown in Fig. 3. In the fields of PRO (Fig. 3a

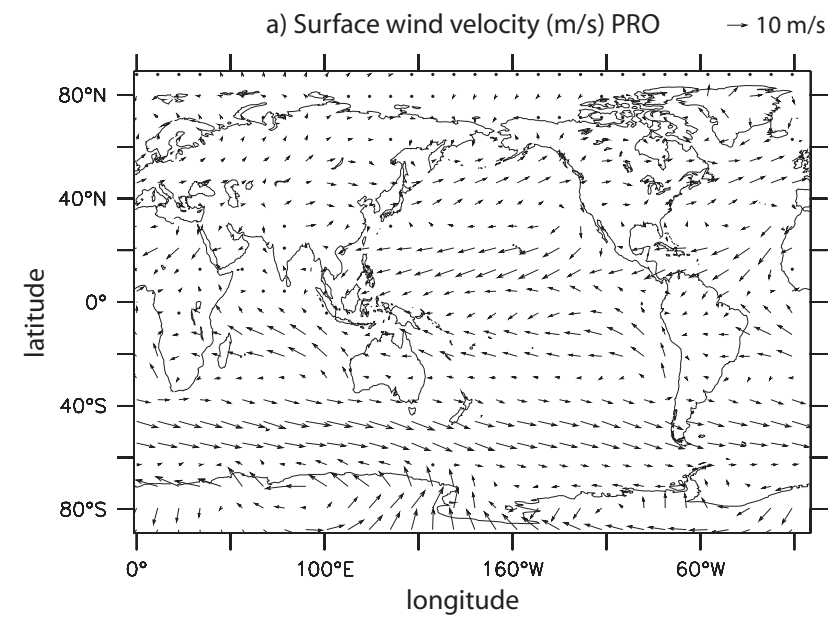

b) Surface wind velocity $(\mathrm{m} / \mathrm{s})$ RETRO $\rightarrow 10 \mathrm{~m} / \mathrm{s}$

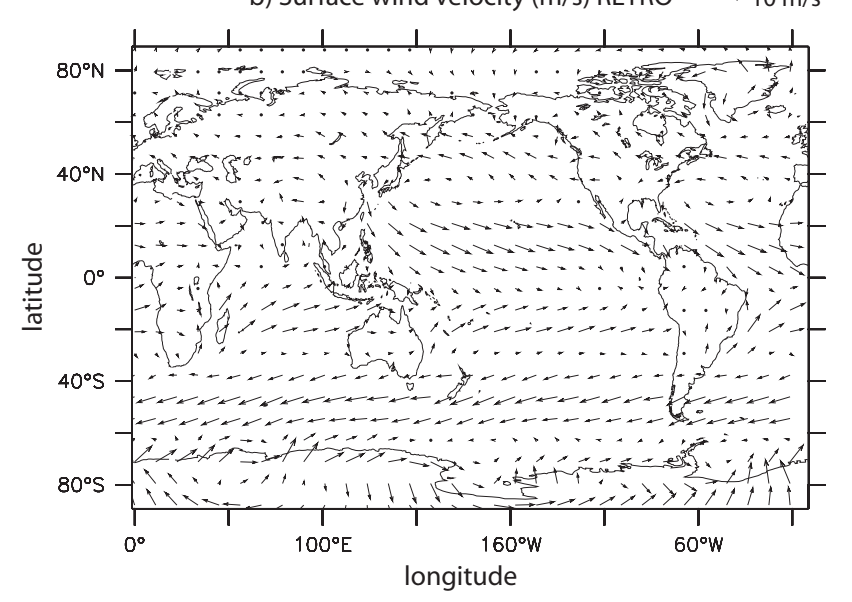

Fig. 2. Surface wind field $\left(\mathrm{m} \mathrm{s}^{-1}\right)$ in (a) PRO and (b) RETRO. The reversal of the surface wind direction in RETRO due to a reversal of the Coriolis parameter can be clearly seen. The equatorial trade winds are westward and the midlatitude winds are eastward on a retrograde rotating earth. The strongest winds still occur over the Southern Ocean. Shown are the means of the years 400-500.

and d), we can identify two zonal asymmetries associated with the ocean circulation. The first asymmetry is due to the gyre transport within the basins. At midlatitudes, the western boundaries of the North Atlantic and the North Pacific are warmer and saltier than the eastern boundaries, because the western boundary currents (i.e., the Gulf stream in the North Atlantic and the Kuroshio in the North Pacific) transport warm and salty water from the subtropics northward. The more striking asymmetry exists between the two basins: the subpolar North Atlantic sea surface is warmer and saltier than the subpolar North Pacific sea surface. This is related to the presence of the Conveyor state of the global MOC with a relatively strong Atlantic MOC (Fig. 1a) and a relatively weak Pacific MOC (Fig. 1b).

The midlatitude asymmetry in the sea surface salinity and sea surface temperature for RETRO (Fig. $3 b$ and e) between 
a) Sea surface salinity (in $\mathrm{g} / \mathrm{kg}$ ) PRO

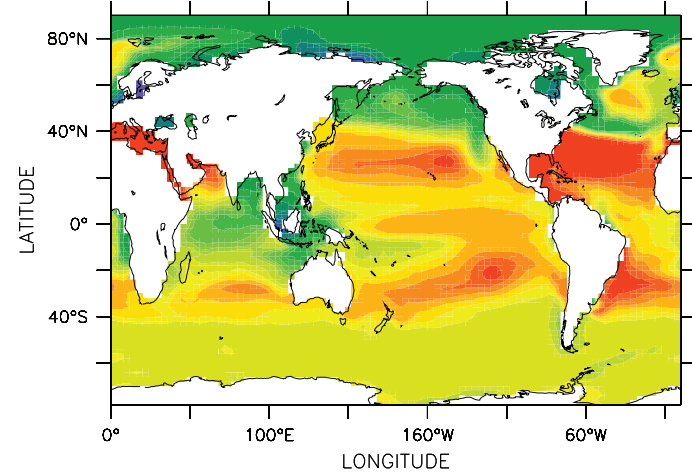

b) Sea surface salinity (in $\mathrm{g} / \mathrm{kg}$ ) RETRO

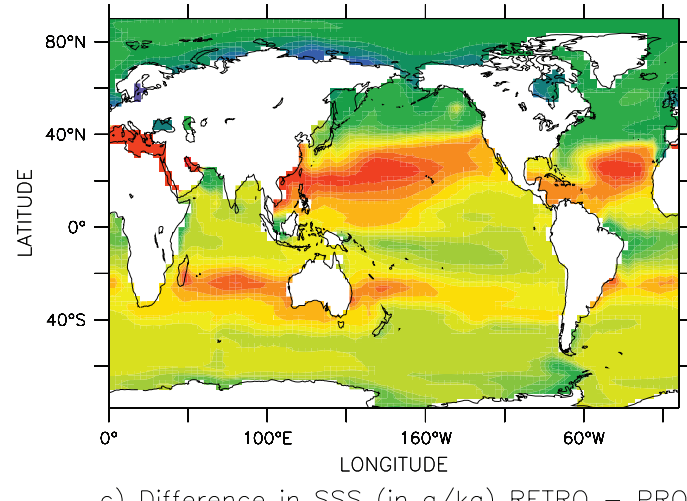

c) Difference in SSS (in $\mathrm{g} / \mathrm{kg}$ ) RETRO - PRO

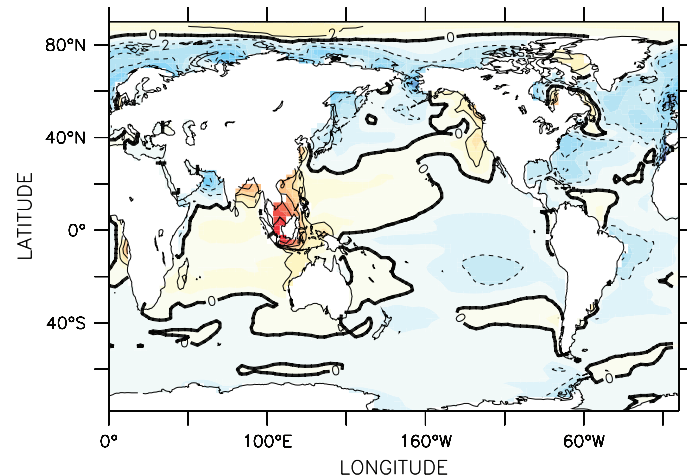

d) Sea surface temperature (in deg C) PRO

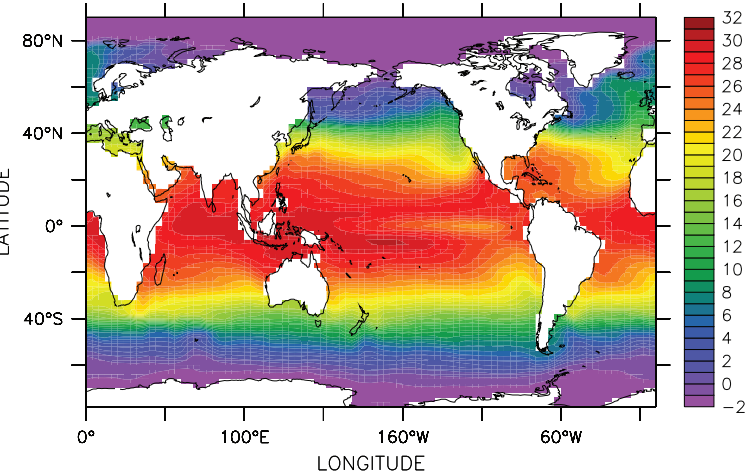

e) Sea surface temperature (in deg C) RETRO

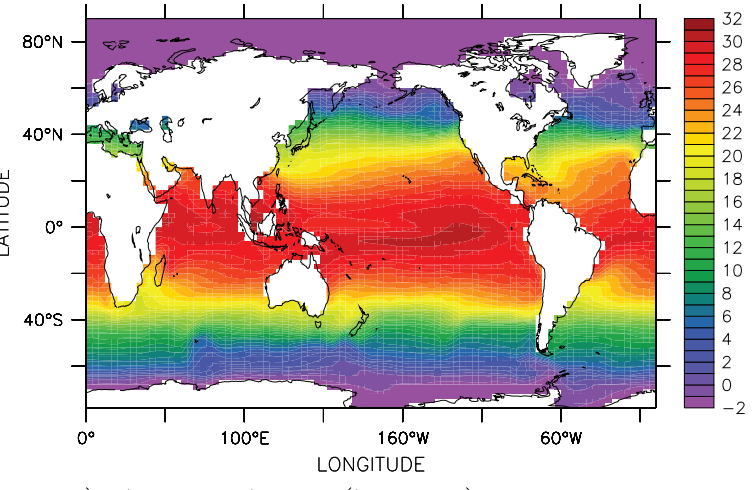

) Difference in SST (in deg C) RETRO - PRO

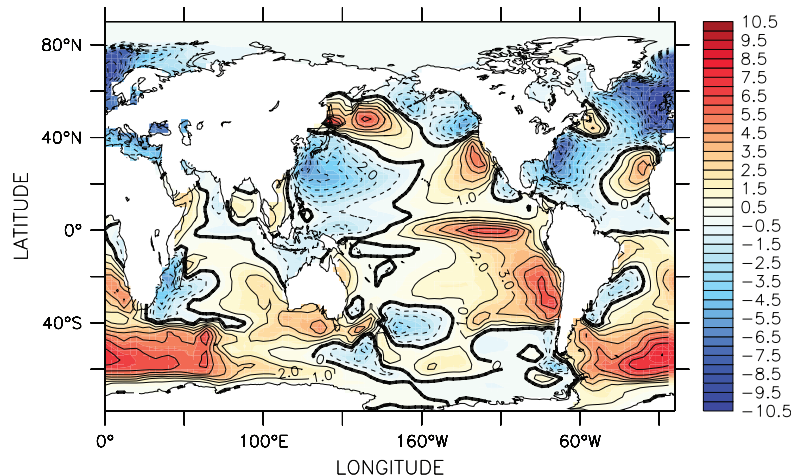

Fig. 3. Sea surface salinity (SSS, g/kg) and sea surface temperature (SST, $\left.{ }^{\circ} \mathrm{C}\right)$. SSS of (a) PRO; (b) RETRO and (c) their difference field; SST of (d) PRO; (e) RETRO and (f) their difference. In the difference field of SSS it is clear that the Atlantic is much fresher in RETRO than in PRO. The SST difference field shows a dipole structure that arises from the reversal of the wind driven gyres. Shown are the means of the years 400-500 of the CCSM3 integration.

the western and eastern boundaries of the basins is reversed with respect to that in PRO. The main reason is that the midlatitude boundary currents in the ocean are located at the eastern basin boundaries on a retrograde rotating earth (while they are located at western boundaries on a prograde rotating earth) as the meridional derivative of the Coriolis parameter (the $\beta$ parameter) has changed sign with respect to that in PRO. In the difference fields between RETRO and PRO (Fig. 3c and $\mathrm{f}$ ) these changes are seen as east-west dipoles in the midlatitude basins. The subpolar North Atlantic sea surface in RETRO is both fresher and colder than in PRO, whereas the subpolar North Pacific in RETRO is saltier than in PRO. A complicating factor is the reversed transport of the Bering Strait, making the surface layers of the North Pacific fresher than expected. Just below the surface, however, the water is much saltier than in PRO.

As is shown in Fig. 4a, the Atlantic MOC in PRO has a maximum strength of about $18 \mathrm{~Sv}$. The Pacific MOC (Fig. 4b) has a strength of about $7 \mathrm{~Sv}$ and is deeper and stronger than estimates from observations, which is a known 

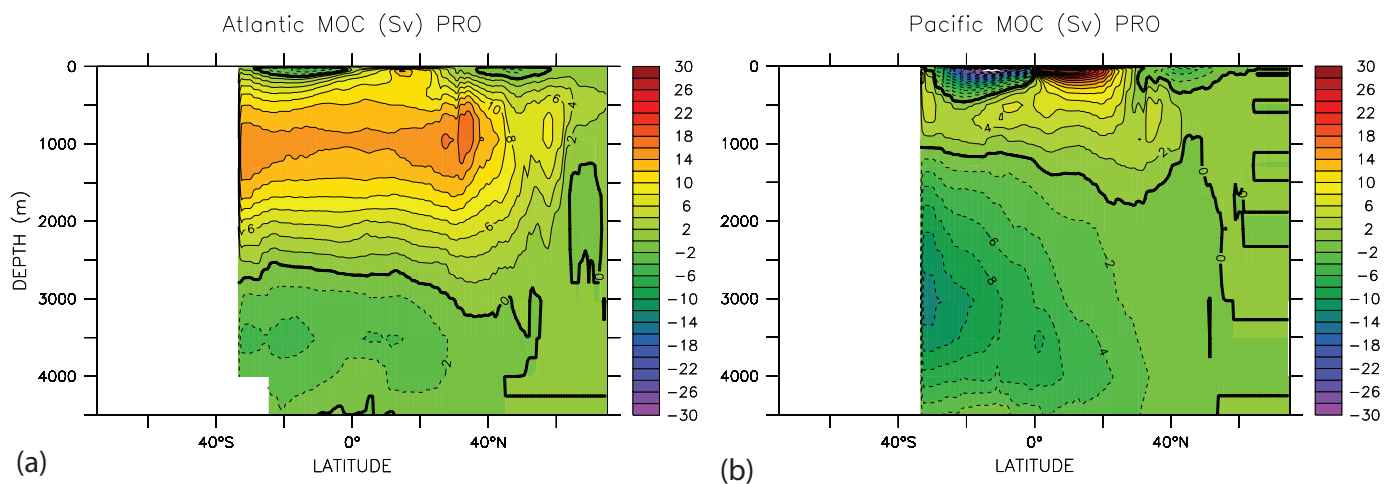

Atlantic MOC (SV) RETRO
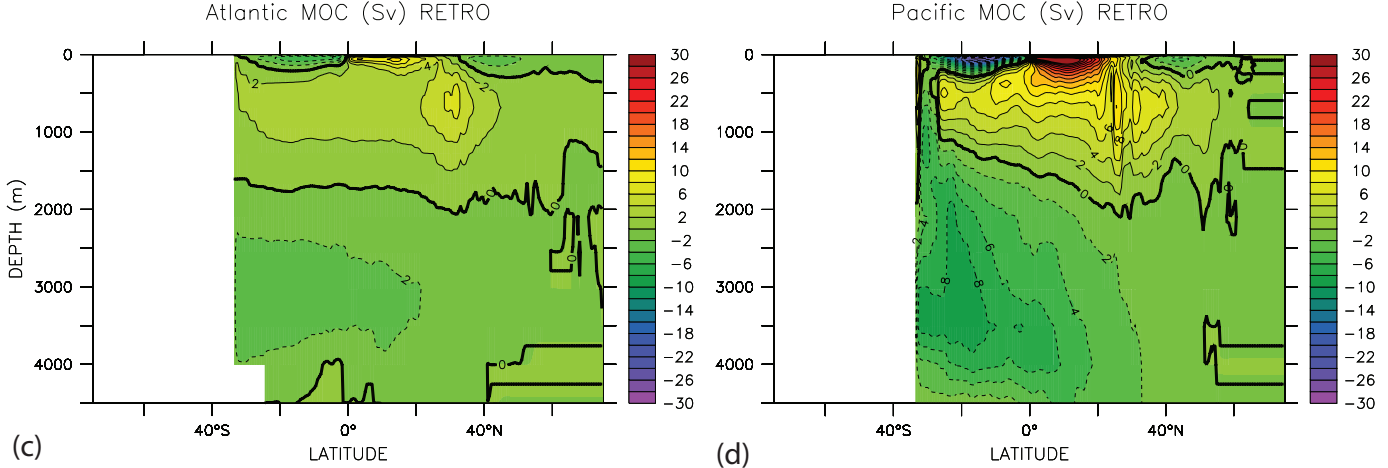

Fig. 4. Meridional overturning streamfunctions (in Sv) in the Atlantic (a) and the Pacific (b) in PRO and in the Atlantic (c) and the Pacific (d) in RETRO. In PRO, we see a Conveyor type solution, with a strong overturning cell in the Atlantic and a minimal overturning cell in the Pacific. In RETRO, the Atlantic MOC is much weaker, and in the Pacific the MOC is stronger, although sinking motion seems to take place at midlatitudes and there is no export to the Southern Ocean. Shown are the means of the years 400-500 of the CCSM3 simulation.

bias of CCSM3 (Thompson and Cheng, 2008). The Atlantic MOC in RETRO (shown in Fig. 4c) is considerably weaker than in PRO and has a maximum varying between 5 and $13 \mathrm{~Sv}$ on multidecadal timescales (Fig. 1a). The Pacific MOC in RETRO (Fig. 4d) has a maximum strength of about $10 \mathrm{~Sv}$, and this maximum occurs at about $25^{\circ} \mathrm{N}$. Analysis of the Pacific mixed layer depth (not shown) shows sporadic deep convection at high northern latitudes and at lower latitudes.

Due to the decrease in the strength of the Atlantic MOC, less warm water is transported from the subtropics into the subpolar North Atlantic. This reduction results in a substantial cooling of the subpolar North Atlantic sea surface. Also, the main wind direction is now from the Eurasian continent, which has a continental climate, resulting in even more winter cooling of the North Atlantic. Consequently, on a retrograde rotating earth, surface temperatures over large parts of Europe are cooler by as much as $10^{\circ} \mathrm{C}$ than in PRO and winter sea ice extends southward up to the Bay of Biscay. The increase in the southward extent of winter sea ice amplifies the cooling of the subpolar North Atlantic, as sea ice reflects more solar radiation than ocean water.

When we take a closer look at the highly variable Atlantic MOC strength in RETRO (Fig. 1a), we find that it has an intermittent character, with short periods of vigorous overturning (Fig. 5a and b), alternated by periods with hardly any deep water formation (Fig. $5 \mathrm{c}$ and d). This is also visible in the mixed layer depth (not shown), which has a maximum around the southern tip of Greenland, 5 to 7 years prior to the maximum overturning. The timescale of the variability is decadal and it requires further study to understand why the amplitude of this decadal oscillation is so pronounced in RETRO.

The weakening of the Atlantic MOC can be expected to be caused by a freshening of the North Atlantic. At least part of the freshening can be explained by the increase in stable precipitation (precipitation in convectively stable environments) over the midlatitude North Atlantic (Fig. 6). Stable precipitation influences the freshwater flux at the sea surface and is, in contrast with evaporation and convective precipitation, for the most part independent of local sea surface temperatures and, thereby, the MOC itself. The increase in stable precipitation over the midlatitude North Atlantic freshens the surface waters which are transported northward by the eastern boundary current. This results in a freshening of the subpolar North Atlantic. Other changes in climate aspects might also contribute to the freshening of the subpolar North Atlantic, including changes in interbasin salinity exchange via ocean pathways.

The surface freshwater flux $(E-P)$, treated as a virtual salt flux and defined positive downward, is shown for PRO 

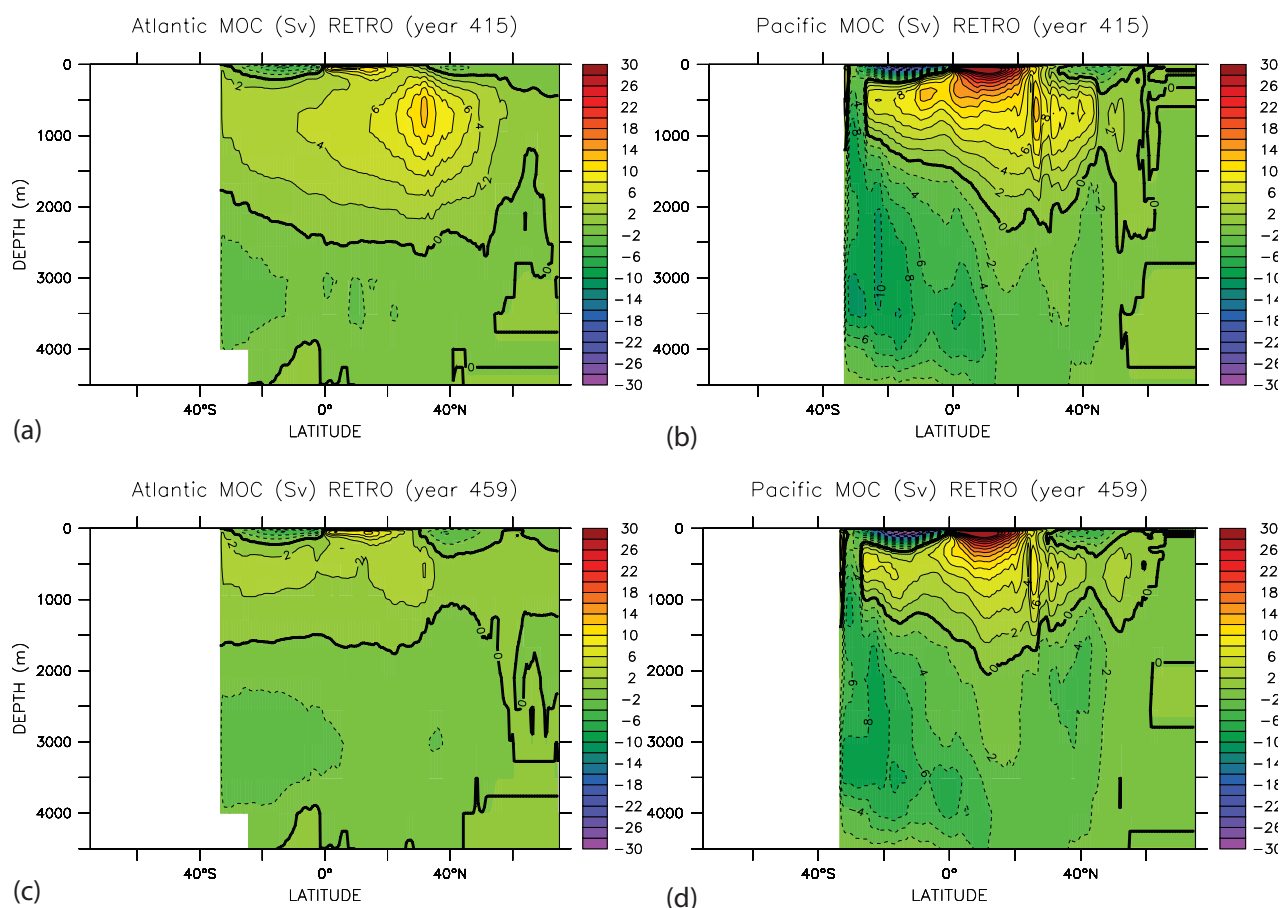

(b)

Pacific MOC (Sv) RETRO (year 459)

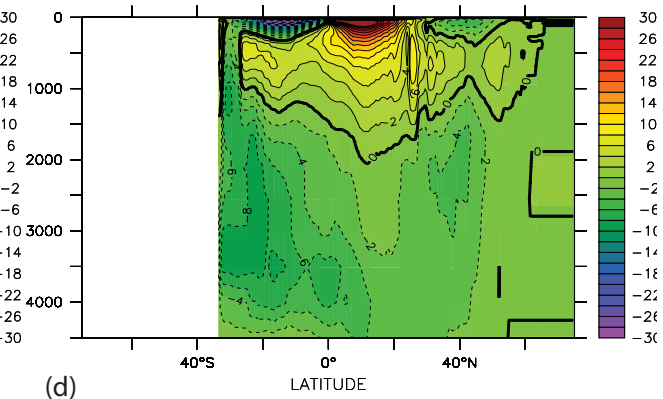

(d)

Fig. 5. Meridional overturning streamfunctions (in Sv) in the Atlantic and the Pacific. (a, b) Strong Atlantic overturning (with a maximum of $13 \mathrm{~Sv}$ ) and (c, d) weak Atlantic overturning.

in Fig. 7a. At tropical and subpolar latitudes, the virtual salt flux is negative due to net precipitation, and at subtropical latitudes, the virtual salt flux is positive due to net evaporation. In PRO, the asymmetry between the North Atlantic and the North Pacific virtual salt flux (Fig. 7a) is clearly seen. At both subtropical and subpolar latitudes, the net flux over the North Atlantic is more salinifying than over the North Pacific. In the view of theory (i), this asymmetry has been suggested to determine the present-day state of the MOC, with deep water formation in the northern North Atlantic, but not in the northern North Pacific. The basinwide freshwater budgets are calculated for the Atlantic (between $32^{\circ} \mathrm{S}$ and $80^{\circ} \mathrm{N}$ ) and the Pacific (between $36^{\circ} \mathrm{S}$ and $70^{\circ} \mathrm{N}$ ). The mean $E-P$ in the Atlantic is $1.01 \mathrm{~kg} \mathrm{~m}^{-2} \mathrm{day}^{-1}$ for PRO and $0.71 \mathrm{~kg} \mathrm{~m}^{-2} \mathrm{day}^{-1}$ for RETRO. The mean $E-P$ in the Pacific is $-0.16 \mathrm{~kg} \mathrm{~m}^{-2} \mathrm{day}^{-1}$ for PRO and $0.07 \mathrm{~kg} \mathrm{~m}^{-2} \mathrm{day}^{-1}$ for RETRO. As expected, the asymmetry in the virtual salt flux field between the North Atlantic and the North Pacific is changed (Fig. 7b) on a retrograde rotating earth (in RETRO), where the Pacific becomes net evaporative. This is mainly due to changes in the freshwater flux in the North Pacific with more net evaporation in subtropical latitudes and less net precipitation in subpolar latitudes.

If the asymmetry in surface freshwater flux would determine the state of the MOC, i.e., view (i), we would expect to find an Inverse Conveyor, with deep water formation in the North Pacific and not in the Atlantic, on a retrograde rotating earth. However, we find a state that has slightly stronger Pacific sinking compared to PRO, but still has a strong and highly variable Atlantic deep water formation.

\section{Stability of the MOC on a retrograde rotating earth}

With the CCSM3 simulation as in the previous section, we have obtained only one quasi-equilibrium state of the global ocean circulation on a retrograde earth. We would also like to compare the sensitivity of the global MOC to changes in the freshwater flux for the PRO and RETRO cases to see whether the salt-advection feedback is able to induce Inverse Conveyor states in the RETRO case. This analysis cannot be done with the CCSM3 and, hence, we use the mean forcing of the CCSM3 in an ocean-only model.

\subsection{Reference states in the ocean-only model}

The ocean-only model used, is the fully-implicit ocean model used in (Dijkstra and Weijer, 2005; Huisman et al., 2010a). The horizontal resolution of the model is about $4^{\circ}$ (a $96 \times 38$ Arakawa C-grid on the domain $\left[180^{\circ} \mathrm{W}, 180^{\circ} \mathrm{E}\right] \times\left[85.5^{\circ} \mathrm{S}\right.$, $\left.85.5^{\circ} \mathrm{N}\right]$ ) and the grid has 12 non-equidistant levels in the 
a) Stable precipitation (in $\mathrm{mm} /$ day) PRO

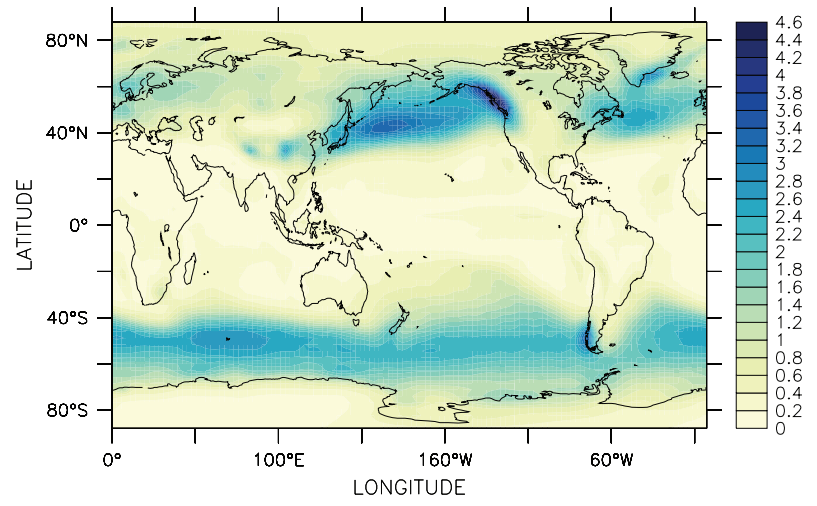

b) Stable precipitation (in $\mathrm{mm} /$ day) RETRO

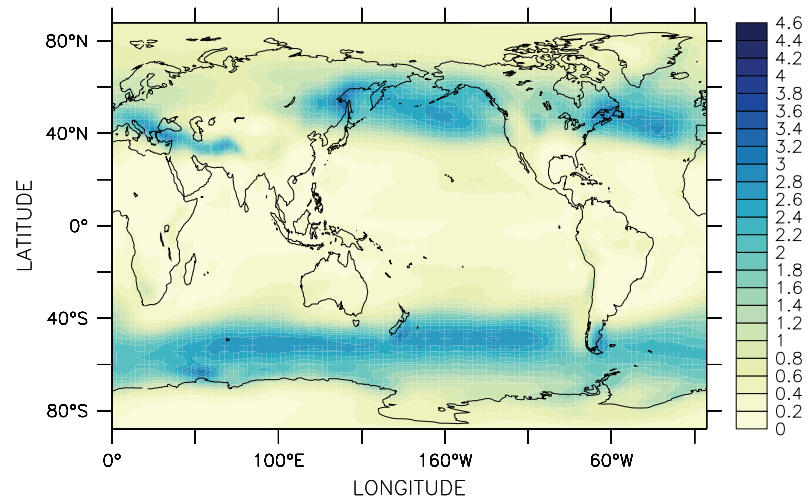

c) Difference in SP (in $\mathrm{mm} /$ day) RETRO - PRO

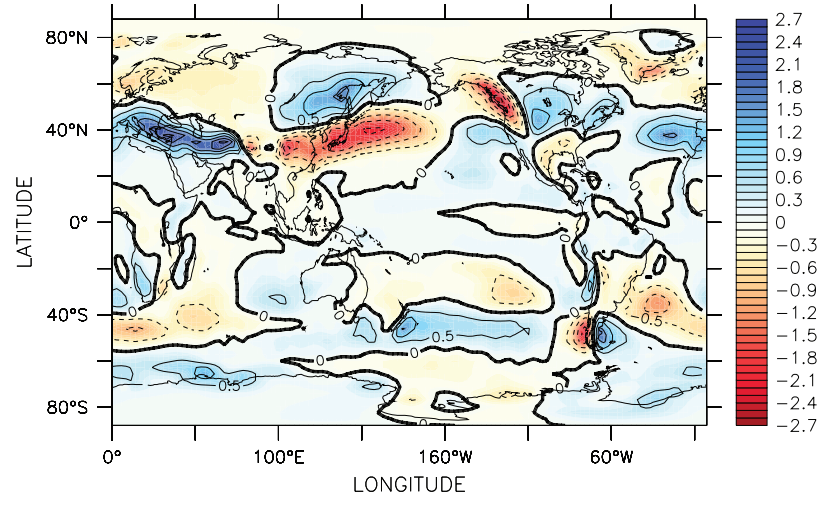

Fig. 6. Stable (non-convective) precipitation (SP) in $\mathrm{mm} \mathrm{day}^{-1}$ in (a) PRO; (b) RETRO and (c) the difference field. The North Atlantic in RETRO receives more (stable) precipitation and the North Pacific receives less. Southern Europe and the Middle East are much wetter in RETRO.

vertical. Details of the model formulation are discussed in Dijkstra and Weijer (2005). The upper ocean is coupled to a simple energy-balance atmospheric model (Dijkstra and Weijer, 2005, Appendix), in which only the heat transport is modelled (and no moisture transport). The special feature of this fully-implicit model is its ability to solve the steady model equations directly without using any time-marching
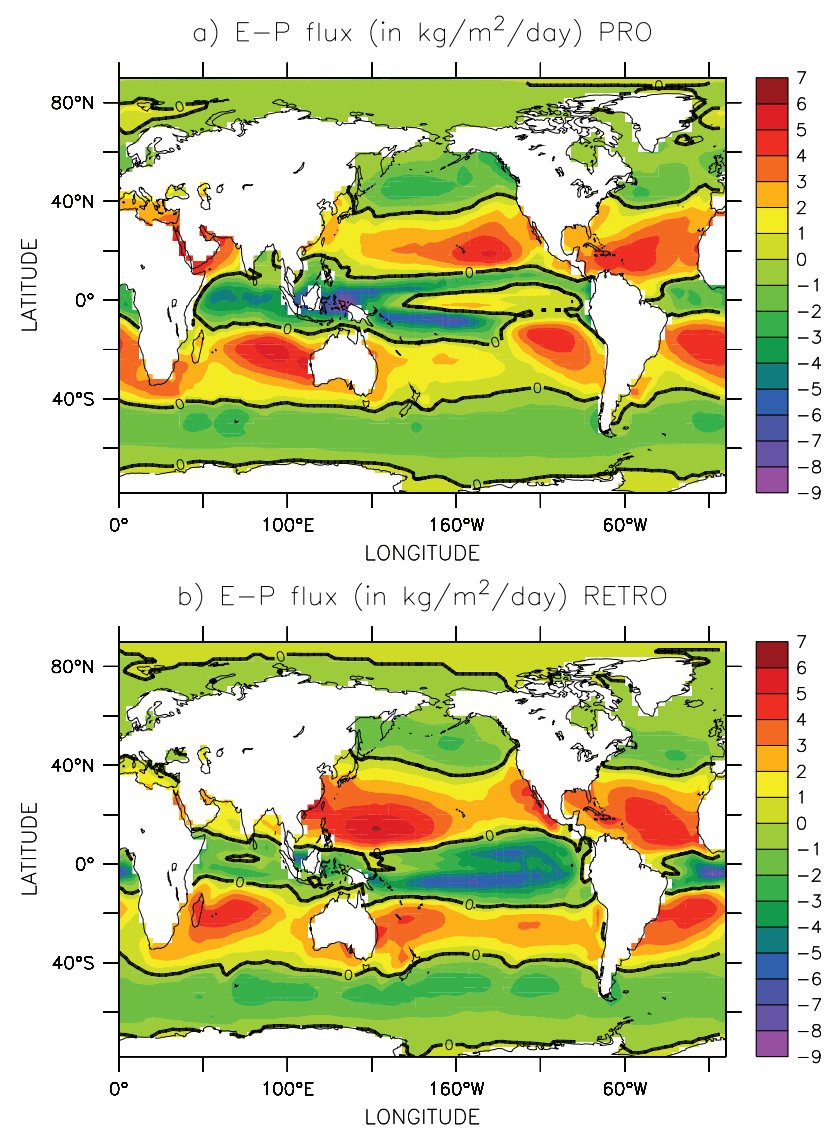

c) Difference in E-P flux (in $\mathrm{kg} / \mathrm{m}^{2} / \mathrm{day}$ ) RETRO - PRO

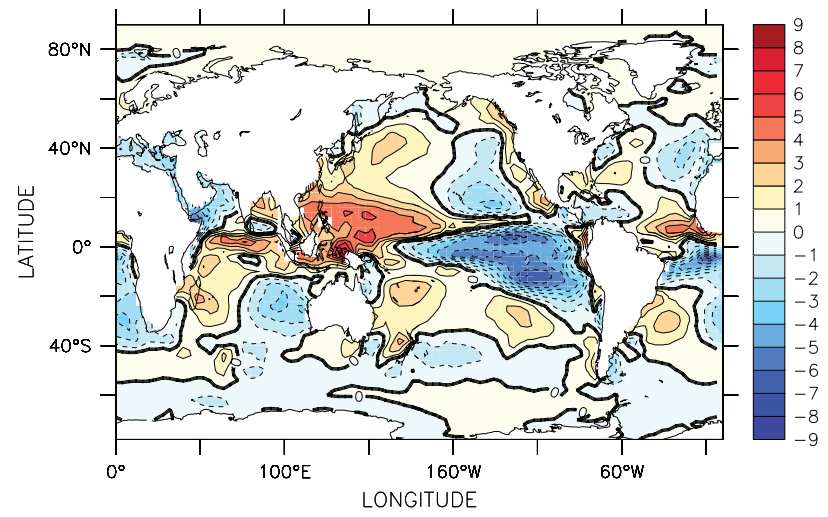

Fig. 7. The virtual salt flux (in $\mathrm{kg} \mathrm{m}^{-2} \mathrm{day}^{-1}$ ), corresponding with the surface freshwater flux $E-P$, in (a) PRO; (b) RETRO and (c) the difference field. In RETRO, the asymmetry in $E-P$ is reversed, mainly due to a decrease in net precipitation at subpolar latitudes and an increase in net evaporation at subtropical latitudes.

techniques, giving the true steady state (with zero model drift) of the system. An additional advantage of the steady state model is that full bifurcation diagrams can be calculated, including unstable steady states.

In the case PRO2, the ocean flow is forced by the annualmean wind stress as given in Trenberth et al. (1989). The 
reference steady state is calculated by restoring the model to the Levitus sea surface salinity field (Levitus, 1982). The reference steady state in $\mathrm{PRO} 2$ and its parameter settings are the same as in Huisman et al. (2010a). From this steady state, the freshwater flux is diagnosed, allowing us to change the surface freshwater flux under mixed boundary conditions. We used this forcing and not the one from the CCSM3 PRO simulation as the bifurcation diagram for $\mathrm{PRO} 2$ was already calculated and analysed in Huisman et al. (2010a). Within the coarse resolution ocean model, we do not expect that the differences in the forcing will lead to substantial changes in the bifurcation diagram.

The reference steady state in case RETRO2 is found by forcing the ocean surface by the quasi-equilibrium surface wind stress field from the CCSM3 RETRO simulation and restoring the model to the quasi-equilibrium salinity field, also from RETRO. More specifically, a continuation path is followed under restoring boundary conditions, starting from the reference steady state in PRO2. First, the wind stress field at the ocean surface is reduced to zero. Secondly, we changed the rotation rate of the earth from $\Omega$ to $-\Omega$. Then, we changed the zero wind stress field at the ocean surface to the quasi-equilibrium wind stress field from RETRO, and the sea surface salinity field to the quasi-equilibrium sea surface salinity field from RETRO. Eventually, we diagnose the freshwater flux from this steady state. This specific path is followed because of the character of the fully-implicit model: equilibrium solutions can be found, provided that the new solution is not too different from the old solution.

\subsection{North Atlantic freshwater flux perturbation}

For both cases PRO2 and RETRO2, a bifurcation diagram with respect to a subpolar North Atlantic freshwater flux perturbation is computed under mixed boundary conditions. For each case, the freshwater flux $F_{\mathrm{S}}$ is given by

$F_{\mathrm{S}}=F_{\mathrm{S}}^{\mathrm{d}}+\gamma_{\mathrm{Atl}} F_{\mathrm{S}}^{\mathrm{p}}-Q$,

where $F_{\mathrm{S}}^{\mathrm{d}}$ is, for each case, the freshwater flux diagnosed from the reference solution and $Q$ is a compensating term to ensure a net zero flux over the total ocean surface. The parameter $\gamma_{\text {Atl }}$ is the amplitude (in Sv) of the freshwater flux perturbation in the North Atlantic over a domain $F_{\mathrm{S}}^{\mathrm{p}}$ that is unity in the area $(\phi, \theta) \in\left[60^{\circ} \mathrm{W}, 24^{\circ} \mathrm{W}\right] \times\left[54^{\circ} \mathrm{N}, 66^{\circ} \mathrm{N}\right]$ (Fig. 8a, inset), and zero elsewhere.

The bifurcation diagram for PRO2 (Fig. 8a), showing the maximum of the Atlantic and Pacific meridional overturning streamfunctions ( $\Psi_{\mathrm{Atl}}$ and $\Psi_{\mathrm{Pac}}$, respectively) versus the parameter $\gamma_{\mathrm{Atl}}$, is extensively described elsewhere (Dijkstra and Weijer, 2005; Huisman et al., 2010a). The upper branch of the bifurcation diagram represents solutions with an Atlantic MOC having deep water formation (Conveyor states). At $\gamma_{\text {Atl }}=0.23 \mathrm{~Sv}$ a saddle-node bifurcation point is reached; marking the transition to the southern sinking solution. The lower branch of solutions corresponds to stable steady states
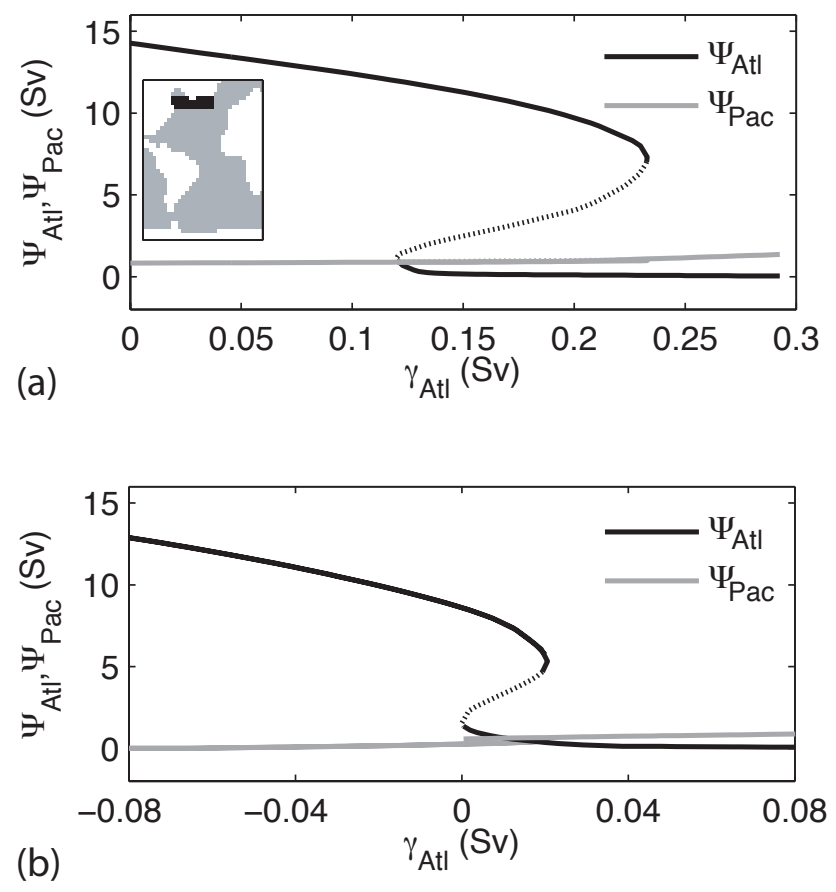

Fig. 8. Bifurcation diagrams under mixed boundary conditions, in which the maximum value of the meridional overturning streamfunction in the Atlantic ( $\Psi_{\text {Atl }}$, black lines) and the Pacific ( $\Psi_{\mathrm{Pac}}$, grey lines) are plotted versus the amplitude of the subpolar North Atlantic and subpolar North Pacific freshwater forcing, $\gamma_{\text {Atl }}$. In (a), $\Psi_{\text {Atl }}$ and $\Psi_{\text {Pac }}$ are shown versus $\gamma_{\text {Atl }}$ for PRO2. The indent shows the area where the perturbation freshwater flux is applied. In (b), $\Psi_{\text {Atl }}$ and $\Psi_{\text {Pac }}$ are shown versus $\gamma_{\text {Atl }}$ for RETRO2. The range for which multiple equilibria exist is much smaller than in PRO2 and is shifted towards smaller values of $\gamma_{\text {Atl }}$, but the shape of the bifurcation diagram is very similar.

without North Atlantic Deep Water formation, in which deep water formation only takes place in the Southern Ocean (the Southern Sinking solution). A second saddle-node bifurcation (at $\gamma_{\mathrm{Atl}}=0.12 \mathrm{~Sv}$ ) is related to the Atlantic MOC recovery. Between the two saddle node bifurcation points, a multiple equilibria regime exists, in which both the Conveyor solution and the Southern Sinking solution exist. In this multiple equilibria regime, also a branch of unstable steady states exists, which cannot be found using a conventional time stepping model. Furthermore, we note that the Pacific MOC is hardly affected by the change in $\gamma_{\text {Atl }}$.

The bifurcation diagram for RETRO2 is shown in Fig. $8 \mathrm{~b}$ and has a shape which is similar to the shape of the bifurcation diagram for PRO2. We identify two stable branches of steady state solutions, connected by a branch of unstable solutions. The upper branch corresponds to the Conveyor solution, whereas the lower branch corresponds to the Southern Sinking solution. Furthermore, we can identify a multiple equilibria regime which is bounded by two saddle-node bifurcation points (at $\gamma_{\mathrm{Atl}} \approx-10^{-4} \mathrm{~Sv}$ and $\gamma_{\mathrm{Atl}}=0.02 \mathrm{~Sv}$ ). 
a) Atlantic streamfunction $\left(\gamma_{\text {Atl }}=0.007 \mathrm{~Sv}\right)$ Conveyor

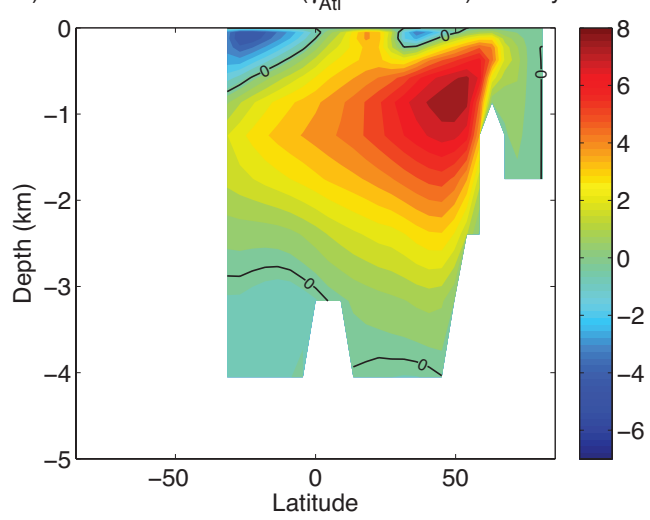

c) Atlantic streamfunction $\left(\gamma_{\mathrm{Atl}}=0.007 \mathrm{~Sv}\right)$ Southern Sinking

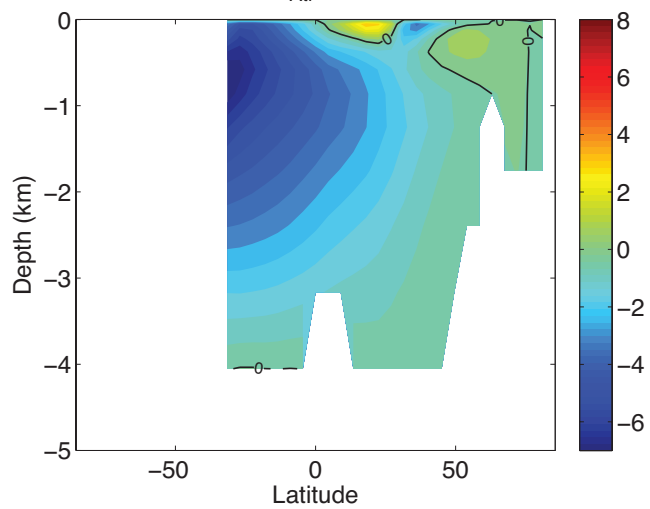

b) Pacific streamfunction $\left(\gamma_{\text {Atl }}=0.007\right.$ Sv) Conveyor

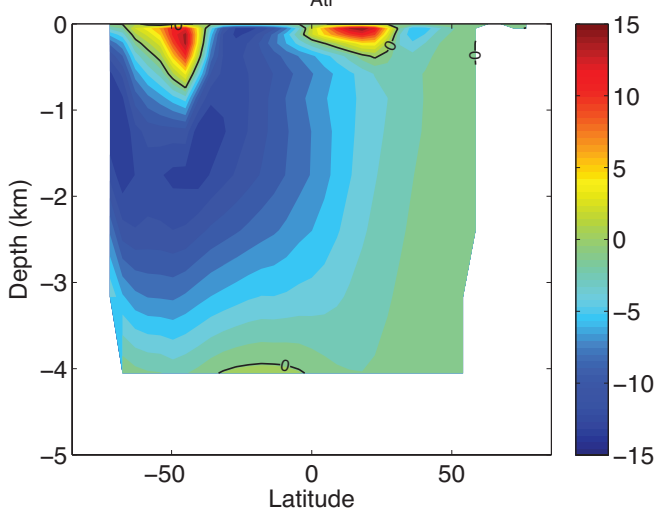

d) Pacific streamfunction $\left(\gamma_{\text {Atl }}=0.007 \mathrm{~Sv}\right.$ ) Southern Sinking

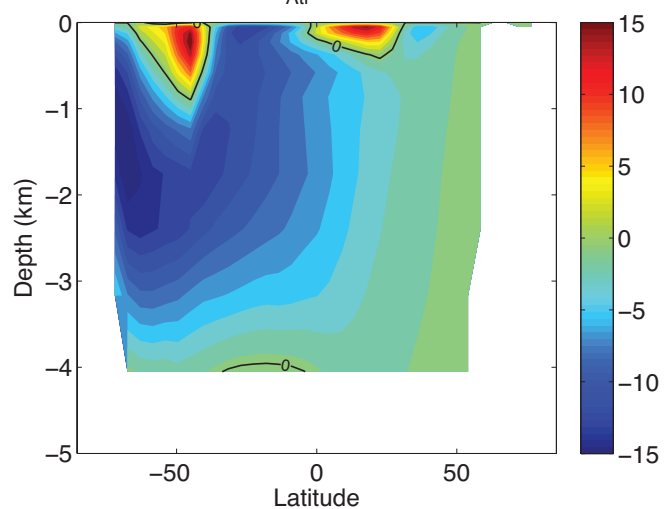

Fig. 9. Atlantic and Pacific meridional overturning streamfunctions in case RETRO2. Because the reference state is very close the saddlenode bifurcation point on the lower branch, the circulation is shown for $\gamma_{\text {Atl }}=0.007 \mathrm{~Sv}$ (see also Fig. 8 and Sect. 4.2 ), a small freshwater perturbation in the North Atlantic. (a) and (b) give the Conveyor-like solution, with positive overturning in the Atlantic and upwelling in the Pacific. (c) and (d) show the Southern Sinking solution with an upwelling cell in both basins.

Because the subpolar North Atlantic is fresher in RETRO2, the bifurcation diagram has shifted to the right, compared to the bifurcation diagram for PRO2.

For $\gamma_{\text {Atl }}=0.007 \mathrm{~Sv}$ the Atlantic and Pacific MOC of the Conveyor state for the case RETRO2 are shown in Fig. 9a and $b$, respectively. The ocean circulation is in a weaker Conveyor state than in PRO2 for a similar value of $\gamma_{\text {Atl }}$. The Atlantic MOC has a strength of $8.0 \mathrm{~Sv}$ and there is no positive Pacific MOC. Due to the relatively large vertical mixing in the model, there is likely an enhanced upwelling within the Atlantic basin, which causes the absence of South Atlantic outflow. The reference steady state solution in RETRO2 (for $\gamma_{\mathrm{Atl}}=0.0 \mathrm{~Sv}$ ) has the same MOC patterns as in Fig. 9a-b and is close to the saddle-node bifurcation point, which marks the transition to the Southern Sinking solution. Therefore, we find that both a Conveyor solution and a Southern Sinking solution exist for $\gamma_{\mathrm{Atl}}=0.0 \mathrm{~Sv}$ in RETRO2. The meridional overturning streamfunctions of the Atlantic and Pacific MOC of the Southern Sinking solution at $\gamma_{\mathrm{Atl}}=0.007 \mathrm{~Sv}$ are shown in Fig. 9c and d. In this steady state, neither a positive Atlantic MOC nor a positive Pacific MOC is present.
The MOC of RETRO2 (Fig. 9) is substantially different from the time-mean MOC of RETRO (Fig. 4). Of course, the implicit ocean model represents a much smaller set of processes than the ocean model of CCSM3. Also because of the large variability of the Atlantic MOC in RETRO, it is hard to judge whether the bifurcation behaviour of RETRO2 is representative for RETRO. However, one can view the results of the different bifurcation diagrams in the implicit ocean model as another indication that on a counterrotating earth, with a reversed $E-P$ forcing, sinking of surface waters is still found in the Atlantic, but not in the Pacific.

\section{Summary and discussion}

In the present-day climate, the Atlantic as a whole is a basin with net evaporation, while the Pacific receives net precipitation. This argument is often used to explain the strong Atlantic-Pacific asymmetry in salinity and meridional overturning circulation, with deep water formation in the North Atlantic, but not in the North Pacific. Here, the question of why such a strong Atlantic-Pacific asymmetry 
exists has been investigated in an innovative way. The coupled atmosphere-ocean-land surface-sea ice model CCSM3 (Collins et al., 2006a) was used to simulate the global MOC on a retrograde rotating earth.

The basic mechanism of the meridional flow response to a meridional density gradient associated with the MOC is invariant to a reversal of the earth's direction of rotation. However, several other climate aspects which influence the MOC are not invariant. On a retrograde rotating earth, the midlatitude boundary currents are relocated at the eastern basin boundaries. Furthermore, the salinity exchange via ocean pathways and freshwater transport via the atmosphere differ on a retrograde rotating earth.

Here, we focussed on the structure of the global MOC and its stability properties on a retrograde rotating earth. While the Atlantic-Pacific asymmetry in $E-P$ is reversed with respect to the prograde rotating case due to changes in precipitation and evaporation patterns, we do not find a simple Inverse Conveyor solution (with deep water formation limited to the North Pacific). Rather, we find a state with increased Pacific intermediate water formation and a weakened Atlantic MOC which is highly variable on multidecadal time scales and certainly still has northern deep water formation. The weakening of the Atlantic MOC is caused by the freshening of the North Atlantic and results in a substantial cooling of the subpolar North Atlantic sea surface. At least part of this freshening can be explained by an increase in stable precipitation over the midlatitude North Atlantic due to a reversed atmospheric flow.

The stability properties of the global MOC on a retrograde rotating earth were analysed using a fully-implicit oceanonly model (Weijer et al., 2003; Dijkstra and Weijer, 2005; Huisman et al., 2010a) using the surface wind stress field and sea surface salinity field from the CCSM3 quasi-equilibrium solution to determine a reference state. The response of the MOC on a retrograde rotating earth to freshwater perturbations in the subpolar North Atlantic surface freshwater flux is similar to the response of the MOC in our present-day climate. The bifurcation diagram has a similar shape and contains a multiple equilibria regime for a range of subpolar North Atlantic freshwater fluxes. Therefore, we conclude that the mechanisms controlling the behaviour of the MOC under such freshwater perturbations are robust under reversal of earth's rotation direction. Indeed, the stability behaviour is mainly governed by the physics of the salt-advection feedback, which is invariant under the rotation reversal.

Based on the results of the CCSM3 and the ocean-only model, we conclude that even when the forcing of the freshwater flux $(E-P)$ is reversed between North Atlantic and North Pacific, a global MOC with North Atlantic deep water formation having similar stability properties as the global MOC on the prograde rotating earth still exists. This suggests that solely the external surface forcing of the ocean circulation is not the dominant factor in setting the large salinity difference and ocean circulation asymmetry between the
Atlantic and Pacific basin. We do not claim that we have falsified the view (i) as presented in the introduction, but we certainly found results (in agreement with those in Huisman et al., 2010b) which do not fit within view (i). Under a reversed freshwater flux, one would expect to find a clear Inverse Conveyor solution. This is not found in either CCSM3 or in the implicit ocean model. A caveat is of course that this result may be model dependent; in the Reversed World simulation of Smith et al. (2008, EGU Poster), only the Inverse Conveyor state was found (in a low resolution AOGCM). We hope that this paper will stimulate this type of numerical experiments in other models so the issue of model dependence can be addressed.

As the external forcing appears not capable of generating the present-day Atlantic-Pacific MOC asymmetry, the origin of this asymmetry may be associated with the selection of the Conveyor state due to external factors according to the view (ii) in the introduction. There are many partial results (Hughes and Weaver, 1994; Dijkstra et al., 2003; Von der Heydt and Dijkstra, 2008; Czaja, 2009) on which factors favour the selection of this state (such as basin size, land-sea contrast, gateway transports, atmospheric circulation, etc.), but all of the studies have been done with rather idealized models. It is, however, clear from these studies that external asymmetries can have more consequences on the existence regime of one type of solution (for example a Southern Sinking solution), than on the existence regime of another type (like a Conveyor solution).

The view above implies that continental geometry is a crucial factor for controlling the global ocean circulation patterns. For example, the meridional extent of the Atlantic is larger than the Pacific, therefore, allowing for colder temperatures and denser waters. The equilibrium ocean circulation pattern under past continental geometries such as in the Eocene, Oligocene or Miocene may depend on subtle differences in the continental geometry of ocean basins, such as the representation of certain gateways, also concluded in Von der Heydt and Dijkstra (2008) based on idealized model studies. It suggests that sensitivity studies with respect to details in past geometries are important in studying the robustness of the global ocean circulation pattern and associated meridional heat transport.

It will be difficult to find support for the view (ii) using present-day simulations in state-of-the-art GCMs as the global Conveyor state may already be unique (due to the external asymmetries all other equilibria do not exist any more). Rather artificial studies would be needed where, for example, the continents are more symmetrized with respect to reality and even then, one probably would have to be lucky to find other equilibria than the Conveyor state. Results from paleoclimate modelling studies, where continents have very different positions, may also provide support for the view (ii) although there are no results yet of multiple MOC equilibria in any paleoceanographic geometry. One would be able to tackle the problem systematically when techniques of 
numerical bifurcation could be applied to full climate models, but that will take considerable time.

In summary, in answering our question from the introduction on why there is a strong present-day Atlantic-Pacific MOC asymmetry, we established that view (i) is not likely correct. However, to obtain convincing support for view (ii), creative model experiments are needed.

Acknowledgements. We thank Michael Kliphuis (IMAU) for technical support. The CCSM3 computations were done on the Huygens IBM Power6 Supercomputer (Huygens) at SARA in Amsterdam. Use of these computing facilities was sponsored by the National Computing Facilities Foundation (N.C.F.) under the project SH084-08 with financial support from the Netherlands Organization for Scientific Research (N.W.O.). Also, we would like to sincerely thank the referees and editor for their competent assessment of and input to the paper.

Edited by: T. Kiefer

\section{References}

Briegleb, B., Bitz, C., Hunke, E., Lipscomb, W., Holland, M., Schramm, J., and Moritz, R.: Scientific description of the sea ice component in the Community Climate System Model, Version 3, Tech. note tn-463+str, National Center for Atmospheric Research, Boulder, CO, 70 pp., 2004.

Collins, W. D., Blackmon, M. L., Bonan, G. B., Hack, J. J., Henderson, T. B., Kiehl, J. T., Large, W. G., McKenna, D. S., Bitz, C. M., Bretherton, C. S., Carton, J. A., Chang, P., Doney, S. C., Santer, B. D., and Smith, R. D.: The Community Climate System Model Version 3 (CCSM3), J. Climate, 19, 2122-2143, 2006 a.

Collins, W. D., Rasch, P. J., Boville, B. A., Hack, J. J., McCaa, J. R., Williamson, D. L., Briegleb, B. P., Bitz, C. M., Lin, S.-J., and Zhang, M.: The Formulation and Atmospheric Simulation of the Community Atmosphere Model Version 3 (CAM3), J. Climate, 19, 2144-2161, 2006b.

Czaja, A.: On the driving processes of the Atlantic meridional overturning circulation, J. Phys. Oceanogr., 39, 234-247, 2009.

Dickinson, R. E., Oleson, K. W., Bonan, G., Thornton, P., Vertenstein, M., Hoffman, F., Yang, Z.-L., and Zeng, X.: The Community Land Model and Its Climate Statistics as a Component of the Community Climate System Model, J. Climate, 19, 2302-2324, 2006.

Dijkstra, H. A. and Weijer, W.: Stability of the global ocean circulation: Basic bifurcation diagrams, J. Phys. Oceanogr., 35, 933948, 2005.

Dijkstra, H. A., Weijer, W., and Neelin, J. D.: Imperfections of the three-dimensional thermohaline ocean circulation: Hysteresis and unique state regimes, J. Phys. Oceanogr., 33, 2796-2814, 2003.

Emile-Geay, J., Cane, M. A., Naik, N., Seager, R., Clement, A. C., and van Geen, A.: Warren revisited: Atmospheric freshwater fluxes and "Why is no deep water formed in the North Pacific", J. Geophys. Res., 108, 3178, doi:10.1029/2001JC001058, 2003.

Ganachaud, A. and Wunsch, C.: Improved estimates of global ocean circulation, heat transport and mixing from hydrographic data, Nature, 408, 453-457, 2000.
Gordon, A. L.: Interocean Exchange of Thermocline Water, J. Geophys. Res., 91, 5037-5046, doi:10.1029/JC091iC04p05037, 1986.

Hughes, T. M. C. and Weaver, A. J.: Multiple Equilibria of an Asymmetric Two-Basin Ocean Model, J. Phys. Oceanogr., 24, 619-637, 1994.

Huisman, S. E., Dijkstra, H. A., von der Heydt, A., and de Ruijter, W. P. M.: Robustness of Multiple Equilibria in the global ocean circulation, Geophys. Res. Lett., 36, L01610, doi:10.1029/2008GL036322, 2009.

Huisman, S. E., den Toom, M., Dijkstra, H. A., and Drijfhout, S.: An Indicator of the Multiple Equilibria Regime of the Atlantic Meridional Overturning Circulation, J. Phys. Oceanogr., 40, 551-567, 2010a.

Huisman, S. E., Dijkstra, H. A., von der Heydt, A., and de Ruijter, W. P. M.: Does net $E-P$ determine the preference for Atlantic sinking?, PhD thesis, Chapter 4, http://www.phys.uu.nl/ $\sim$ shuisman/JPOsubmitted/ (last access: April 2011), 2010b.

Kuhlbrodt, T., Griesel, A., Montoya, M., Levermann, A., Hofmann, M., and Rahmstorf, S.: On the driving processes of the Atlantic meridional overturning circulation, Rev. Geophys., 45, RG2001, doi:10.1029/2004RG000166, 2007.

Levitus, S.: Climatological Atlas of the World Ocean, NOAA Professional Paper, 1982.

Marotzke, J.: Abrupt climate change and thermohaline circulation: Mechanisms and predictability, P. Natl. Acad. Sci., 97, 13471350, doi:10.1073/pnas.97.4.1347, 2000.

Marotzke, J. and Willebrand, J.: Multiple equilibria of the global thermohaline circulation, J. Phys. Oceanogr., 21, 1372-1385, 1991.

Meehl, G. A., Washington, W. M., Arblaster, J. M., and Hu, A.: Factors affecting climate sensitivity in global coupled models, J. Climate, 17, 1584-1596, 2004.

Rahmstorf, S., Crucifix, M., Ganopolski, A., Goosse, H., Kamenkovich, I., Knutti, R., Lohmann, G., Marsh, R., Mysak, L. A., Wang, Z., and Weaver, A. J.: Thermohaline circulation hysteresis: A model intercomparison, Geophys. Res. Lett., 32, L23605, doi:10.1029/2005GL023655, 2005.

Schmittner, A., Silva, T. A. M., Fraedrich, K., Kirk, E., and Lunkeit, F.: Effects of Mountains and Ice Sheets on Global Ocean Circulation, J. Climate, doi:10.1175/2010JCLI3982.1, in press, 2011.

Smith, R. and Gent, P.: Reference manual for the Parallel Ocean Program (POP): Ocean component of the Community Climate System Model (CCSM2.0 and 3.0), Tech. rep. laur-02-2484, Los Alamos National Laboratory, Los Alamos, NM, 75 pp., 2004.

Smith, R. S., Gregory, J. M., Thorpe, R. B., and Rodriguez, J.: Response of the meridional overturning circulation in an idealised reverse world experiment, EGU General Assembly, session CL26 poster; Ref. No.: EGU2008-A-06893, 2008.

Stommel, H.: Thermohaline convection with two stable regimes of flow, Tellus, 13, 224-230, 1961.

Thomas, D. J.: Evidence for deep-water production in the North Pacific Ocean during the early Cenozoic warm interval, Nature, 430, 65-68, doi:10.1038/nature02639, 2004.

Thompson, L. A. and Cheng, W.: Water Masses in the Pacific in CCSM3, J. Climate, 21, 4514-4528, 2008.

Trenberth, K. E., Olson, J. G., and Large, W. G.: A global ocean wind stress climatology based on ECMWF analyses, Tech. rep., National Center for Atmospheric Research, Boulder, CO, USA, 
1989.

Von der Heydt, A. and Dijkstra, H. A.: The effect of gateways on ocean circulation patterns in the Cenozoic, Global Planet Change, 62, 132-146, 2008.

Weijer, W. A. D. H., Öksüzoglu, H., Wubs, F. W., and de Niet, A. C.: A fully-implicit model of the global ocean circulation, J. Comput. Phys., 192, 452-470, 2003.
Wunsch, C.: Towards understanding the Paleocean, Quaternary Science Reviews, 29, 1960-1967, 2010.

Zaucker, F., Stocker, T. F., and Broecker, W. S.: Atmospheric freshwater flux and their effect on the global thermohaline circulation, J. Geophys. Res., 99, 12443-12457, 1994. 